\title{
Doctor Controllable Artificial Pancreas System
}

\author{
Arivan R.V ${ }^{1}$, Harish Kumar $\mathrm{S}^{1}$, Subhashini $\mathrm{A}^{2}$ \\ ${ }^{1}$ Student, Computer Science and Engineering, Dhanalakshmi College of Engineering, Chennai-601 301 \\ ${ }^{2}$ Assistant Professor, Computer Science and Engineering, Dhanalakshmi College of Engineering, Chennai-601 301.
}

\begin{abstract}
The artificial pancreas device system is an automated glucose control system that closely mimics the glucose regulating function of a healthy pancreas. In this paper, we describe a system that is partially doctor controllable and is used to automatically control blood sugar in people with type 1 diabetes through the fully automated measurement of blood glucose levels and the delivery of insulin and glucagon. We also take into account the varieties of insulin available and their effective time. When a patient's blood sugar is too high, insulin is given to the patient to bring the blood sugar back to a normal level. To prevent a patient's blood sugar from going too low, the patient is given glucagon which raises the patient's blood sugar back to a normal level. The whole system can be controlled and under observation by a doctor.
\end{abstract}

Key Words: Continuous glucose monitor, insulin, glucagon, controller.

\section{INTRODUCTION}

Diabetes is a chronic, disease, in which the body either cannot produce insulin or cannot properly use the insulin it produces. Insulin is a hormone that controls the amount of glucose in the blood. Type 1 diabetes occurs when the immune system mistakenly attacks and kills the beta cells of the pancreas and the body cannot produce insulin further. Type 2 diabetes occurs when the body can't properly use the insulin that is released by the pancreas. The blood sugar of a patient with diabetes can go too low - a condition called hypoglycemia, if left untreated can lead to feelings of discomfort, seizures, and in rare cases brain damage or death. Diabetes patients can also suffer from excessively high blood sugar - a condition called hyperglycemia. Exposure to hyperglycemia over many years can cause neuropathy, retinopathy, and damage to other tissue and organs. Current methods of maintaining blood glucose in patients with diabetes involves periodic monitoring of blood sugar using blood glucose monitors and then subsequent delivery of insulin via either multiple needle injections throughout the day or alternatively through the use of an insulin pump. The disadvantage with this method is that there is no real time monitoring of blood glucose in between the infused time. The artificial pancreas device is a system of devices that closely mimics the glucose regulating function of a healthy pancreas [1]. In this paper we'll be discussing an algorithm for artificial pancreas system that allows the device to be partially controlled by the doctor in terms of amount of insulin or glucagon to be infused and when to fit and remove the device. We also propose a live monitoring system to the doctor. Artificial pancreas systems is most effective with type 1 diabetes as glucose regulatory system is completely absent in them. Type 2 diabetes is more complex to handle using an artificial pancreas system. The artificial pancreas system focuses on reducing the side effects caused due to abnormalities in glucose levels in between the infusion time in current methods [2]. It also takes the prescription of the doctor so that the device operates in control and the probability of infusing wrong amount of insulin/glucagon is reduced. As shown in Figure 1 below a patient's blood glucose level may vary a lot in between the infusion time due to infusion of fixed amount of insulin at fixed intervals.

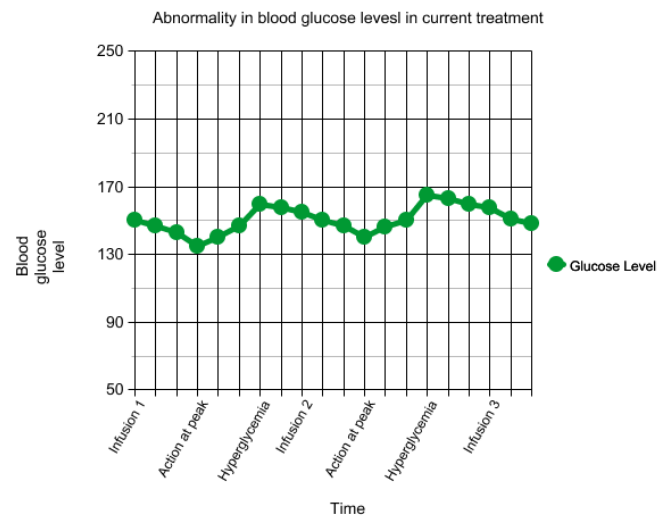

Fig. 1 Abnormalities in blood glucose level in current methods of diagnosis

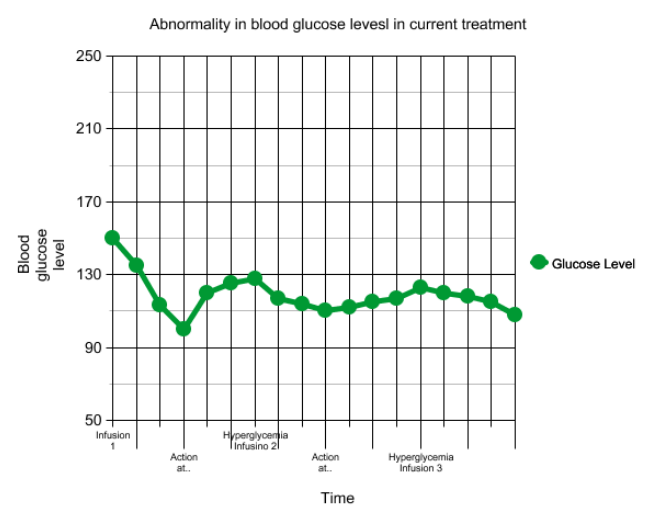

Fig. 2 Blood glucose levels without any peaks using artificial pancreas system. 
On the other hand person using an artificial pancreas system has the blood sugar levels maintained between 80-120 $\mathrm{mg} / \mathrm{dL}$, and has his infusion rates dynamically varied according to the current blood glucose levels. The artificial pancreas system tries to reduce the overall increase and decrease of blood glucose levels of a patient as show in the above Figure 2.

\section{MAterials AND METHODS}

\section{A. Architecture}

Artificial pancreas systems consists of three types of devices a continuous glucose monitoring system (CGM), an insulin/glucagon infusion pump and a controller that automatically adjusts the delivery of insulin and glucagon. An algorithm decides the amount of insulin/glucagon to be infused.

1) Continuous Glucose Monitor: Unlike a blood glucose meter (BGM), which provides just a single glucose reading, CGM systems provide real-time, dynamic glucose information every five minutes. It also gives valuable insight about glucose levels, speed of infusion and direction giving you additional insight to proactively manage your diabetes. It has a small sensor that measures glucose levels just underneath the skin and a transmitter that fits onto the sensor and sends data wirelessly to the cloud storage [3]. Free style libre CGMs and Dexcom CGMs are typical examples.

2) Infusion Pump: An infusion pump is a small, and computerized device that is programmed to deliver insulin or glucagon into the fatty tissue under the skin. The infusion pump is durable and lasts for years. The reservoir is a container where insulin and glucagon is stored and is replaceable, the tubing connects the reservoir to the subcutaneous route and infusion set mechanically pumps the insulin/glucagon from reservoir to the tubing into the body. The amount to be pumped is fed from the controller. MiniMed $670 \mathrm{G}$, Animas vibe are typical examples.

3) Controller: Controller controls and co-ordinates the continuous glucose monitor and infusion pump. It reads the current blood glucose level that is stored in the cloud, and feeds the infusion pump the amount of insulin/glucagon to be infused [4]. The Controller can be a micro controller like Atmega328 or a micro processor like Raspberry Pi. It will be most effective if we use a micro controller since it performs repetitive tasks like getting values from the cloud and feeding corresponding insulin/glucagon values to the infusion pump again and again. The micro controller can be made to communicate with the cloud and the infusion pump using a GSM module like SIM800L or wifi module like ES8266-01. In case of Raspberry $\mathrm{Pi}$ it has in build communication channels like bluetooth and wifi. A typical controller with wifi module may look like Figure 3.

\section{B. Algorithm}

The algorithm determines the amount of insulin or glucagon to be infused to the person. Our proposed algorithm repeatedly reads the blood glucose values through a continuous glucose monitor and sends it to a private cloud

Vol. 1 (12), June 2018, www.ijirase.com storage. The controller reads the blood glucose values from the cloud and feeds corresponding insulin/glucagon to be infused to the infusion pump.

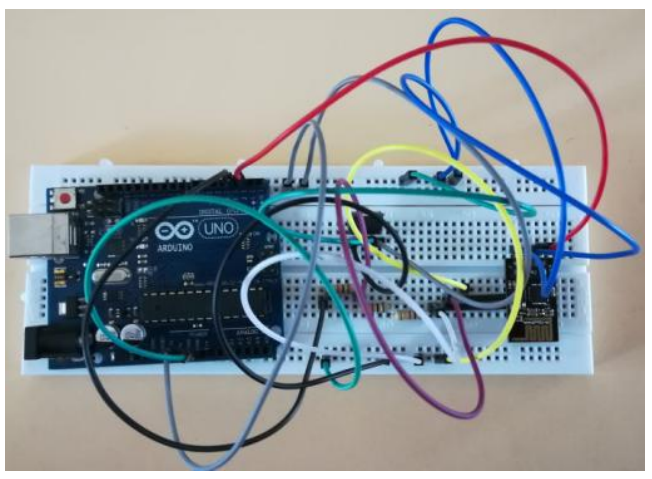

Fig. 3 Arduino UNO based microcontroller with ESP8266-01 wifi module for communication.

Since there are more number of insulin types each and every insulin have its own onset time, peak activity time, time they are effective in person's body, and we cannot design a generalised pancreas system that is suitable for all types of insulin and glucagon. Figure 4 shows different types of insulin and their rough Insulin actions, onset, peak activity and durations. Hence we consider a doctor's prescription for the amount of insulin/glucagon to be infused to a person based upon his blood glucose levels. Doctors can prescribe the amount based on a patient's glycated haemoglobin level $(\mathrm{HbA} 1 \mathrm{c})$ or speed of infusion of insulin/glucagon in the blood plasma cells obtained from the CGM [5]. They will be having an interface where in the doctor can give units of insulin/glucagon to be infused for certain blood glucose range. For example a doctor may prescribe that if the patient's blood sugar level rises for about $5 \mathrm{mg} / \mathrm{dL}$ than the targeted blood glucose level then based on insulin action dynamics the system must give a dosage of 3 units plus bolus units of insulin in order to bring back to the targeted blood glucose level. Similarly the doctor has to furnish the dosage for both hyperglycemia and hypoglycemia. These values are fed into the controller and it is properly coded so that it communicates with the cloud and infusion pump.

\begin{tabular}{||c|c|c|c||}
\hline Insulin & Onset begins & $\begin{array}{c}\text { Peak activity } \\
\text { occurs }\end{array}$ & $\begin{array}{c}\text { Duration after } \\
\text { injecting }\end{array}$ \\
\hline $\begin{array}{c}\text { Analogue } \\
\text { rapid }\end{array}$ & $\begin{array}{c}\text { Within } 15 \\
\text { mins }\end{array}$ & $\begin{array}{c}15 \text { mins to } 1 \\
\text { hour }\end{array}$ & 3 to 4 hours \\
\hline Human short & $\begin{array}{c}\text { Within } 30 \\
\text { mins }\end{array}$ & 1 to 3 hours & 6 to 8 hours \\
\hline Animal short & Within 1 hour & 2 to 5 hours & 6 to 8 hours \\
\hline $\begin{array}{c}\text { Human } \\
\text { intermediate }\end{array}$ & Within 2 hours & 2 to 12 hours & 18 to 24 hours \\
\hline $\begin{array}{c}\text { Animal } \\
\text { intermediate }\end{array}$ & Within 2 hours & 6 to 12 hours & 18 to 24 hours \\
\hline $\begin{array}{c}\text { Analogue long } \\
\text { Anithin } 1 \text { hour }\end{array}$ & $\begin{array}{c}\text { No peak as } \\
\text { such }\end{array}$ & 18 to 24 hours \\
\hline $\begin{array}{c}\text { Analogue } \\
\text { ultra-long }\end{array}$ & Within 1 hour & $\begin{array}{c}\text { No peak as } \\
\text { such }\end{array}$ & $\begin{array}{c}\text { More than } 42 \\
\text { hours }\end{array}$ \\
\hline Animal long* & 4 to 6 hours & 10 to 20 hours & 28 to 36 hours \\
\hline Fig.
\end{tabular}

action dynamics.

1) Insulin Calculation: The algorithm starts by infusing basal units which is the background insulin units to be infused 
in between the meal time. Basal unit is calculated by using a person's weight.

Basal Unit $=50 \%($ Weight of a patient in lbs. $\div 4)$

If a patient's body is very resistant to insulin, the basal units may be high and if the body is sensitive to insulin, the patient may require a lower insulin dose. The basal insulin units to be delivered can be broken down into 16 smaller units because the insulin activity time for a person will be over in 90 minutes [9] at the worst case, if the person is highly resistant to insulin. So the continuous blood glucose monitor will check the patient's blood glucose level every 90 minutes and will determine the amount of insulin to be infused. A typical flow chart of the algorithm will be like as shown in Figure 5.

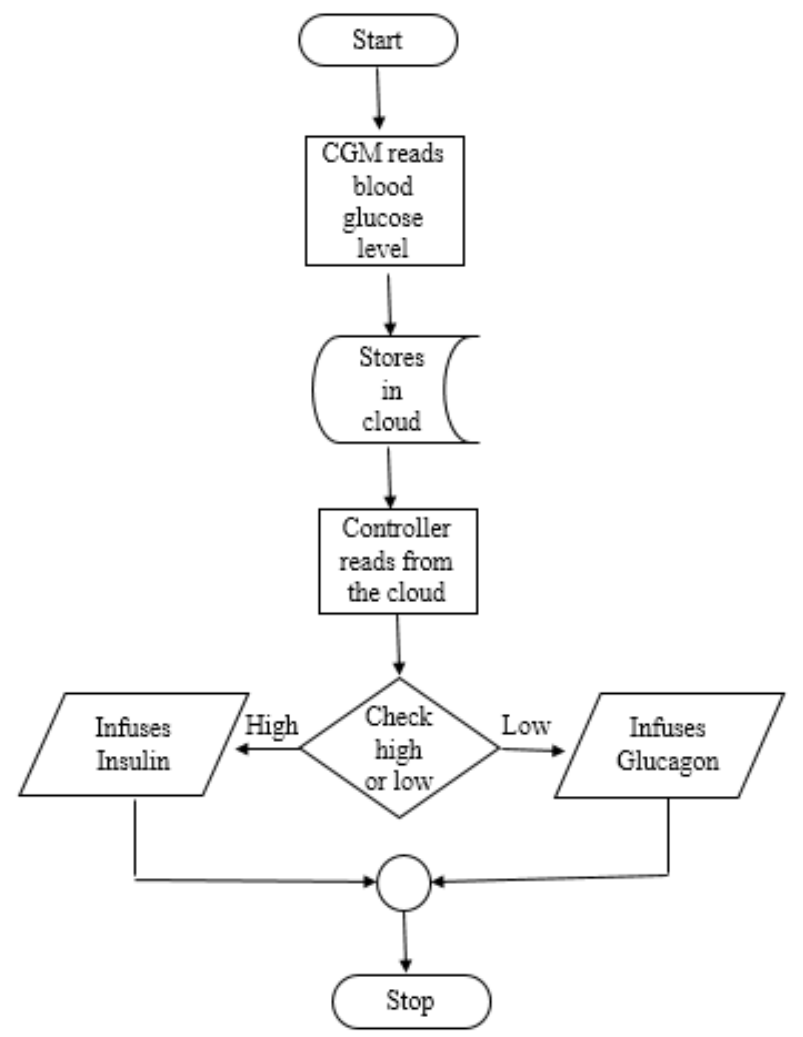

Fig. 5 A typical flow chart for Bi-hormonal artificial pancreas system.

The bolus units are added to the basal unit if the patient's blood sugar is more than the targeted blood sugar level. The bolus units are added in order to correct the excess carbohydrates that are consumed by the person. Increase in blood sugar level is the difference between the current blood glucose level and the targeted blood glucose level. The correction factor of insulin can be obtained by dividing 1800 by basal insulin units [6].

One unit of insulin correction factor $=1800 \div$ basal unit Bolus units can be calculated by dividing increase in blood glucose level by correction factor of insulin used.
Bolus Unit $=$ Increase in blood glucose level $\div$ Correction Factor

The total units to be infused can be calculated as the sum of basal units and bolus units. The general target for blood glucose level is usually set between 100 to $120 \mathrm{mg} / \mathrm{dL}$. Figure 6 shows a typical architecture for artificial pancreas system.

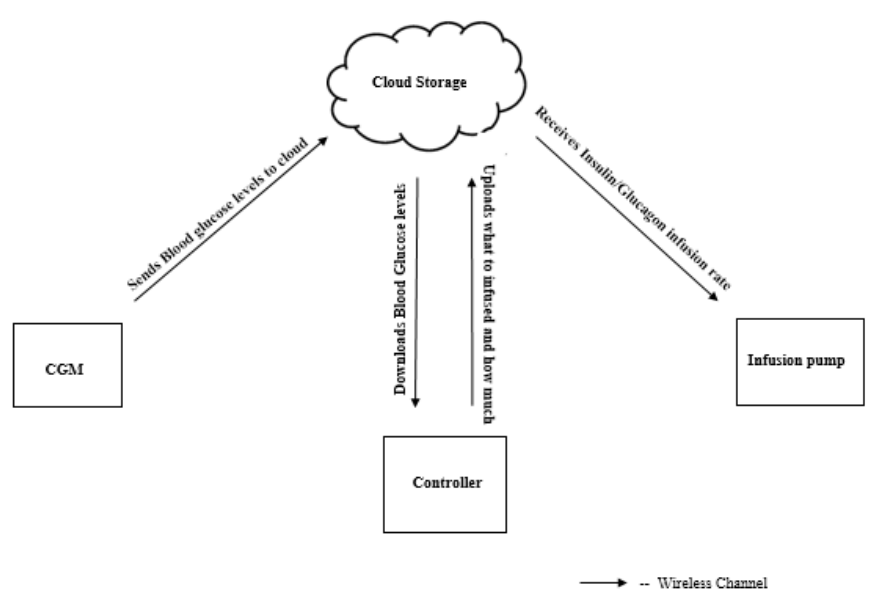

Fig. 6 A typical architecture for artificial pancreas system.

2) Glucagon Calculation: Glucagon infused in case if the blood glucose level of a patient is lower than $40 \mathrm{mg} / \mathrm{dL}$ [7]. The insulin infusion is stoped until the blood glucose level comes back to the normal level. Mostly a shot of $3 \mathrm{mg} / \mathrm{dL}$ of glucagon is given to the patient which will bring back the blood glucose level between the range 50 to $100 \mathrm{mg} / \mathrm{dL}$, After 90 minutes the algorithm checks blood glucose levels and continues to infuse insulin/glucagon as necessary.

\section{Alerting System}

The System sends alert to the doctor responsible through a mobile device as an alarm. The alarm is triggered if the patient's blood sugar level goes below $40 \mathrm{mg} / \mathrm{dL}$ as hypoglycaemia and with the amount of glucagon/insulin infused previously [8], if it goes beyond $200 \mathrm{mg} / \mathrm{dL}$ as hypoglycaemia and with the amount of glucagon/insulin infused previously. The doctor also has a facility to monitor the patient's blood glucose level currently and the history of blood glucose level and the amount of insulin/glucagon infused.

\section{CONCLUSIONS}

The Artificial pancreas system is a long-awaited goal for management of type 1 diabetes, and its development was recently triggered by the development of continuous glucose sensors. It controls the diabetes more efficiently by taking into consideration the types of insulin varieties involved and their infusion, reaction rates. It provides an improved alerting and monitoring system to the doctor. 


\section{REFERENCES}

[1] Ralf Dudde, Thomas Vering, Gundula Piechotta, and Rainer Hintsche, "Computer-Aided Continuous Drug Infusion: Setup and Test of a Mobile Closed-Loop System for the Continuous Automated Infusion of Insulin", (IEEE Transactions on Information Technology in Biomedicine, Vol. 10, No. 2, April 2006).

[2] Vladim'ır Batora, Marian $T$ arn, Jan Murga, Signe Schmidt, Kirsten Nørgaard, Niels Kjøstad Poulsen, Henrik Madsen, Dimitri Boiroux and John Bagterp Jørgensen, "The Contribution of Glucagon in an Artificial Pancreas for People with Type 1 Diabetes",( 2015 American Control Conference Palmer House Hilton July 1-3, 2015).

[3] Charrise M. Ramkissoon, Brian Aufderheide, B. Wayne Bequette and Josep Vehi, "A Review of Safety and Hazards Associated with the Artificial Pancreas", (IEEE Reviews in Biomedical Engineering, Vol. 7, No. 8, Feburary 2015).

[4] Jan-Philipp Stauffert, Florian Nieblingy and Marc Erich Latoschik, "Reducing Application-Stage Latencies For Real-Time Interactive Systems", (IEEE 9th Workshop on Software Engineering and Architectures for Real time Interactive Systems (SEARIS) 201620 March).

[5] A. Rodríguez-Herrero, C. Pérez-Gandía, E.J. Gómez and M.E. Hernando, "A Simulation Study of an Adaptive Inverse Controller for Closed-Loop Control in Type 1 Diabetes", (Bioengineering and Telemedicine Journal, Universidad Politécnica de Madrid, 28040 Spain).

[6] Stephen D. Patek1, Sanjian Chen, Patrick Keith-Hynes, and Insup Lee, "Distributed Aspects of the Artificial Pancreas", (Fifty-first Annual Allerton Conference Allerton House, October 2 - 3, 2013).

[7] Peter G. Jacobs, Joseph El Youssef, Jessica R. Castle, Julia M. Engle, Deborah L.Branigan, Phillip Johnson, Ryan Massoud, Apurv Kamath and W. Kenneth Ward, "Development of a fully automated closed loop artificial pancreas control system with dual pump delivery of insulin and glucagon", (33rd Annual International Conference of the IEEE EMBS Boston, Massachusetts USA, August 30 - September 3, 2011).

[8] Pau Herrero, Mohamed El Sharkawy, Peter Pesl, Monika Reddy, Nick Oliver, Des Johnston, Chris Toumazou and Pantelis Georgiou, "Live Demonstration: A Handheld Bio-inspired Artificial Pancreas for Treatment of Diabetes", (IEEE Transactions on Information Technology in Biomedicine, Vol. 14, No. 2, May 2011).

[9] Ankush Chakrabarty, Stamatina Zavitsanou, Francis J. Doyle III and Eyal Dassau, "Event-Triggered Model Predictive Control For Embedded Artificial Pancreas Systems", (IEEE Transactions on Information Technology in Biomedicine, Vol. 10, No. 2, April 2000. 